\title{
Using Importance-Performance Analysis in Evaluating Taiwan Blog e-Service Quality
}

\author{
Yu-Kai Huang, Wei-Shang, Fan, Ming-Chun Tsai, and Ying-Hui Ho
}

\begin{abstract}
This study uses Importance-Performance Analysis (IPA) in evaluating Taiwan blog e-service quality. Base on Importance-Performance Analysis, if the interface is smooth, and it provides multiplicity and uploading functions belonged to quadrant 1, (keep up the good work), and the most important blogs' future functions is sharing resources between blogs associated with quadrant 1 , (keep up the good work). Finally, the result of this study is expected to serve as a useful guideline for Internet service providers and future research. Implications of these results for practice and research are provided as result.
\end{abstract}

Index Terms-Blog, e-service quality, importance-performance analysis.

\section{INTRODUCTION}

What are Blogs? How and when did they first appear? Wikipedia defines a Blog (a contraction of the term "Web $\log ")$ as a kind of website usually maintained by an individual, a Blogger, who regularly enters comments, descriptions of events, or other material such as graphics or video. Entries are commonly displayed in reverse-chronological order. The word "Blog" can also be used as a verb, meaning to maintain or add content to a Blog. Hsu and Lin [1] mention that Blogs first appeared in 1999 with the object of commenting on politics, and it certainly caused an increase in campaign funding for many candidates. Blogs attracted immediate attention once they had been introduced into politics and these "Poliblog" commentaries had a tremendous influence on elections.

According to Wikipedia explained that many blogs provide commentary or news on a particular subject; others function as more personal online diaries. A typical blog combines text, images, and links to other blogs, Web pages, and other media related to its topic. The ability for readers to leave comments in an interactive format is an important part of many blogs. Most blogs are primarily textual, although some focus on art (artlog), photographs (photoblog), sketches (sketchblog), videos (vlog), music (MP3 blog), audio (podcasting), which are part of a wider network of social media. Micro-blogging is another type of blogging, one which consists of blogs with very short posts.

Manuscript received October 22, 2013; revised December 23, 2013.

Y. K. Huang is with the Department of Culture and Creative Enterprise Management, Nanhua University, 62249, Chiayi, Taiwan (e-mail: osilo.huang@gmail.com).

W. S. Fan is with the Department of Business Administration, Nanhua University, 62249, Chiayi, Taiwan (e-mail: wsfan@mail.nhu.edu.tw).

M. C. Tsai is with the Program in Business, Feng Chia University, 40042, Taichung, Taiwan (e-mail: mctsai@gmail.com).

Y. H. Ho is with the kingstone.com, 10009, Taipei, Taiwan (e-mail: wwwcandy00@yahoo.com.tw).
Blogs first appeared less than ten years ago but the information explosion has caused their usage to grow exponentially. Blogs are in use throughout the world and have become a tool of the masses. The last decade has also seen much importance placed on blog research. Because of this rapid growth many people simply do not understand what blogs are, or how they are used. Four million blogs could be found on the Internet five years after they first appeared in 1999. However, by December 2013 the blog search engine Technorati (http://technorati.com/) was tracking more than 150 million different blogs. According to these data, the effect on the traditional media and publishing must be very great.

Todoroki, Konishi, and Inoue [2] said that blog-based research notebook enables us to manage all the personal information electronically, which was formerly recorded in our paper-based notebooks. This service requires user authentication function in a user-installed server and infrastructure for "blogging anytime, anywhere"'. Once these are satisfied, the blog acts as a personal informatics workbench; a gateway to all the information needed which is traceable and retrievable. Although some existing knowledge-sharing systems also have electronic notebook service as their front-end, the present and existing notebooks should be properly used depending on the purpose, managing personal information or promoting knowledge-sharing. The growth of Weblogs, also abbreviated to blogs, on the Internet has been phenomenal. Originally an online writing tool that helped its users keep track of their own online records, the blog quickly turned into a key part of online culture. The method provides an easy way for an average person to publish material of any topic he or she wishes to discuss in a web site. With a popular issue, a blog can attract tremendous attention and exert great influence on society [3].

The study's motivates, in our changing technological environment the World Wide Web, plays a very important part. This fast developing technology has made it possible for people to interact in ways that were impossible before. This phenomenal increase in the exchange of ideas between people has many perspectives that can be investigated.

There are little technical knowledge is needed to set up and run a Blog. All you need to establish your own Blog or Blogs is a computer and an Internet connection. You will not only be able to share articles, your personal feelings, pictures and videos, but you can also make friends and share your opinions with anyone or everyone else you encounter on the Internet. Using a Blog to express your opinions will also improve, and perhaps also change, the style of both your writing and reading. This study explores the phenomenon of the Blog in Taiwan. This is a worthwhile pursuit that gives us 
much food for thought. How can it be possible for 112 million blogs to be created in under 10 years? The study also explores the attraction blogging has for the user and also attempts to make some suggestions that might help Blog providers improve their services.

\section{PROCEDURE FOR PAPER SUBMISSION}

\section{A. E-Service Quality}

The last few decades have seen growing interest and importance placed on research in the definition, modeling, and measurement of service quality. Parasuraman, Zeitithaml and Berry proposed that service quality has four distinguishing characteristics: (1) Service quality is more difficult for the customer to evaluate than goods quality; (2) Service quality perceptions result from a comparison of consumer expectations with actual service performance; (3) Quality evaluations are not made solely on the outcome of a service; they also involve evaluations of the process of service delivery; (4) Services cannot be stored and carried forward to a future time period [4].

As the Internet has remained a crucial channel for selling most types of merchandise and services, the issue of understanding electronic services has recently received considerable attention in academic research. Ruyter et al. [5] described Electronic service (E-Service) as "providing a superior experience to consumers with respect to the interactive flow of information". Accordingly, on-line service can be divided into a functional dimension (what is delivered in term of service outcome) and a technical dimension (how is it delivered in term of service process), Grönroos et al. [6]. provided a definition of NetOffer model. Many researchers thought that the definition of e-service should include all cues and encounters that occur before, during and after the electronic service delivery.

Parasuraman et al. [7]. proposed that service quality is a function of the gap between expected service and perceived service. They developed a model of service quality by an exploratory investigation of quality in four retail consumers including appliance maintenance, retail banking, securities brokers, and credit card services. This model based on the gaps between consumers and marketers, and it is widely called "PZB model" or "GAP model". According to the study, ten key dimensions about service quality were introduced in 1985, and then refined into five dimensions named SERVQUAL in 1988 for measuring customers' subjective perception of service quality.

E-Ratings, a section of a well-known magazine for rating the quality of products and services, Consumer Reports evaluates the quality of service provided on a website. There are three criteria that E-Ratings use to evaluate a website: credibility, usability and content. Similarly, BizRate.com creates a measurement based on ten dimensions to evaluate e-service quality. The "Webby Awards" from the International Academy of Digital Arts and Science also has their own criteria for evaluating the quality of a website. Final, the award for website quality given by Worldbestwebsites.com evaluates quality by five criteria.

Additional research has expanded the use of SERVQUAL to other areas including retail consumers of health care, residential utility, job placement, retail store, pest control, dry cleaning, financial service, and fast-food services found the resultant dimensions have ranged from one to eight [8].

Several researchers have criticisms for the SERVQUAL. For example, estimation of customer perception may already include perception minus the expectation mental process, and SERVQUAL applications in different industries reveal that 5 dimensions may not cover aspects of customer service present in all service encounters.

The five dimensions in SERVQUAL and SERVPERF models can measure service quality well in off-line environments, however, on-line services have unique characteristics that should be contained, for example, connectivity and server problems [9]. There are more and more researches focus on e-service quality recently. The first definition of e-service quality is that service quality on the Internet is the extent to which a website facilitates efficient and effective shopping, purchasing, and delivery of products and services [10].

Loiacono, Watson, and Goodhue developed WebQual, a scale with 12 dimensions to improve the service quality of websites [11]. However, this study generated information for website designers, rather than measuring service quality, so WebQual may be insufficient. Yoo and Donthu developed a scale called SITEQUAL to measure site quality on four dimensions [12]. Since the data for developing and testing SITEQUAL were gathered from students who did not have to complete the purchasing process, it does not constitute a comprehensive assessment of a site's service quality. By using an on-line survey, Wolfinbarger and Gilly developed a scale called eTailQ. This scale of e-service quality has four dimensions: Website design, reliability/fulfillment, privacy/security, and customer service [13].

Collier and Bienstock measured service quality in E-Retailing and they developed a conceptual framework of e-service quality [14]. This research focused not only on website interactivity or process quality but also on outcome quality and recovery quality. It consisted of three second-order dimensions and eleven first-order dimensions: privacy, design, information accuracy, ease of use, functionality, order timeliness, order accuracy, order condition, interactive fairness, procedural, and outcome fairness. In order to integrate both utilitarian and hedonic e-service quality elements, Bauer, Falk, and Hammer developed a transaction process-based scale for measuring service quality (eTransQual). The five dimensions in eTransQual are functional/design, enjoyment, process, reliability and responsiveness [15].

\section{B. Importance-Performance Analysis}

Importance-Performance Analysis (IPA) is a simple and useful technique for identifying those attributes of a product or service that are most in need of improvement or that are candidates for possible cost-saving conditions without significant detriment to overall quality. The application of IPA, introduced by Martilla and James is well documented and has shown the capability to provide service managers with valuable information for both satisfaction measurement and the efficient allocation of resources in an easily 
applicable format [16].

IPA, first introduced by Martilla and James, they pointed out that IPA is a simple and effective technique that can assist practitioners in identifying improvement priorities for service attributes and direct quality-based marketing strategies. Practitioners apply IPA to analyze two dimensions of service attributes: performance level (satisfaction); and, importance to customers. Analyses of these dimension attributes are then integrated into a matrix that helps a firm identify primary drivers of customer satisfaction and, based on these findings, set improvement priorities [17]. About IPA that attribute importance is depicted along the $\mathrm{X}$-axis and attribute performance (satisfaction or service quality) is depicted along the y-axis [18].

IP maps highlight the relative positions of attributes in matrix format, with the importance values on the vertical axis and performance values on the horizontal axis. E-service quality and logistics service quality questionnaire items are classified into quadrants as shown in the graph: quadrant I (improvement reinforcement area), quadrant II (maintenance reinforcement area), quadrant III (secondary improvement area) and quadrant IV (over-emphasized area).

\section{1) Quadrant I}

Both performance and importance are high, indicate opportunities for achieving or maintaining competitive advantage and are major strengths. The management scheme for this quadrant is "keep up the good work."

\section{2) Quadrant II}

Performance is low and importance is high that require immediate attention for improvement and are major weaknesses. The management scheme for this quadrant is "concentrate here."

\section{3) Quadrant III}

Performance and importance are low and that are minor weaknesses and do not require additional effort. The management scheme for this quadrant is "low priority.",

\section{4) Quadrant IV}

Performance is high and importance is low, indicate that business resources committed to these attributes would be overkill and should be deployed elsewhere. These attributes are minor strengths. The management scheme for this quadrant is "possible overkill."

The study will apply the IPA technique to analyze users' performance and importance of using blog.

\section{DATA AND ANALYSIS RESUltS}

\section{A. Data Collect}

Data was collected by a web survey located on a portal, http://210.17.21.66/CVSVote3.htm. In order to increase the response rate of blog participants, we placed messages about the survey on more than ten online message boards that had heavy traffic:

- Google (http://blogsofnote.blogspot.com/)

- MSN (http://home.live.com/)

- PChome (http://mypaper.pchome.com.tw/)

- Xuite (http://blog.xuite.net/)
- Yahoo (http://tw.blog.yahoo.com/)

- Wretch (http://tw.blog.yahoo.com/)

- PIXNET (http://www.pixnet.net/)

- Roodo (http://blog.roodo.com/)

- Sina (http://blog.sina.com.tw/)

The survey notice was left on these boards, and some others, for a month and a half. The samples: 729 on-line questionnaires and 221 printed ones were returned. Of this 950 total returned, 900 were effectively useable.

The overall amount of data in this analysis dataset is 971 including 71 non-returns and 900 returns. Analysis of the respondents: $70.1 \%$ are female; $46.3 \%$ are in the $21-25$ age groups; $69.8 \%$ are in college; most are students $51.3 \%$; $85.7 \%$ are single; $65.8 \%$ of the respondents had not incomes in excess of 20,000 NTD and $45.6 \%$ respondents live in the south. We can also found that we found most writers' classification about top 3 was:

- Mood class group are $47.7 \%$.

- Private class space group are $10.6 \%$.

- Entertainment class group are $9.2 \%$.

- And most readers' classified top 3 were:

- Entertainment class group are $18.9 \%$

- Mood class group are $11.1 \%$

- Private space class group are $10.5 \%$.

TABLE IA: DEMOGRAPHIC CHARACTERISTICS

\begin{tabular}{|c|c|c|}
\hline Classification & Number Of respondents & Percentage \\
\hline \multicolumn{3}{|l|}{ Gender } \\
\hline Male & 269 & 29.9 \\
\hline Female & 631 & 70.1 \\
\hline \multicolumn{3}{|l|}{ Location } \\
\hline North & 278 & 30.9 \\
\hline Middle & 177 & 19.7 \\
\hline South & 410 & 45.6 \\
\hline East & 22 & 2.4 \\
\hline Of-shore island & 5 & 0.6 \\
\hline Other & 8 & 0.9 \\
\hline \multicolumn{3}{|l|}{ Occupation } \\
\hline Agriculture & 7 & 0.8 \\
\hline Manufacturing & 49 & 5.4 \\
\hline Service & 94 & 10.4 \\
\hline Freedom & 33 & 3.7 \\
\hline Student & 462 & 51.3 \\
\hline Education & 63 & 7.0 \\
\hline Government & 11 & 1.2 \\
\hline Electronics & 40 & 4.4 \\
\hline Soldier & 35 & 3.9 \\
\hline Housewife & 34 & 3.8 \\
\hline Other & 72 & 8.0 \\
\hline \multicolumn{3}{|l|}{ Age } \\
\hline Under 20 & 190 & 21.1 \\
\hline $21-25$ & 417 & 46.3 \\
\hline $26-30$ & 152 & 16.9 \\
\hline $31-35$ & 90 & 10.0 \\
\hline $36-40$ & 32 & 3.6 \\
\hline $41-45$ & 11 & 1.2 \\
\hline Old then 46 & 8 & 0.9 \\
\hline \multicolumn{3}{|l|}{ Marriage } \\
\hline Single & 771 & 85.7 \\
\hline $\begin{array}{l}\text { Marriage } \\
\text { (no children) }\end{array}$ & 103 & 11.4 \\
\hline $\begin{array}{l}\text { Marriage } \\
\text { (have children) }\end{array}$ & 26 & 2.9 \\
\hline \multicolumn{3}{|c|}{ To play role on the blog Writer } \\
\hline Writer & 254 & 28.2 \\
\hline Reader & 446 & 49.6 \\
\hline Only read & 200 & 22.2 \\
\hline
\end{tabular}


Experience with Blogs: $49.0 \%$ have been using the Internet for more than 7 years; $62.6 \%$ are in the 3 hours and over Internet access time groups; $79.3 \%$ have their own Blogs and $63.3 \%$ are using Wretch. $54.1 \%$ of the respondents were in the 30 minutes and over reading and writing Blog time groups and $77.8 \%$ had experience in writing Blogs (See Table IA).

TABLE IB: DEMOGRAPHIC CHARACTERISTICS (CON)

\begin{tabular}{|c|c|c|}
\hline Classification & Number Of respondents & Percentage \\
\hline \multicolumn{3}{|c|}{ To often read and write article' classification } \\
\hline Entertainment & 98 & 11.4 \\
\hline Financial & 20 & 2.3 \\
\hline Family life & 22 & 2.6 \\
\hline Food & 36 & 4.2 \\
\hline Health & 8 & 0.9 \\
\hline Life & 16 & 1.9 \\
\hline Digital life & 2 & 0.2 \\
\hline Sport & 22 & 2.6 \\
\hline Art & 25 & 2.9 \\
\hline Public theme & 4 & 0.5 \\
\hline Game & 13 & 1.5 \\
\hline Esthetics & 5 & 0.6 \\
\hline Education & 10 & 1.2 \\
\hline Image create & 10 & 1.2 \\
\hline Pet & 27 & 3.1 \\
\hline Video & 22 & 2.6 \\
\hline Mood & 341 & 39.6 \\
\hline Technology & 7 & 0.8 \\
\hline Photography & 12 & 1.4 \\
\hline Travel & 7 & 0.8 \\
\hline Job & 4 & 0.5 \\
\hline Fashion & 39 & 4.5 \\
\hline Schoolyard & 20 & 2.3 \\
\hline Private space & 91 & 10.6 \\
\hline \multicolumn{3}{|c|}{ To often read and write blog's platform } \\
\hline Google & 13 & 1.5 \\
\hline Msn & 48 & 5.4 \\
\hline PChome & 9 & 1.0 \\
\hline Xuite & 29 & 3.3 \\
\hline Yahoo & 134 & 15.1 \\
\hline Wretch & 560 & 63.3 \\
\hline PIXNET & 27 & 3.1 \\
\hline Roodo & 5 & 0.6 \\
\hline Sina & 3 & 0.3 \\
\hline Other & 57 & 6.4 \\
\hline \multicolumn{3}{|c|}{ To read and write blog's time } \\
\hline Under 30 minutes & 413 & 45.9 \\
\hline 30-60 minutes & 332 & 36.9 \\
\hline 1-2 hours & 120 & 13.3 \\
\hline 3-4 hours & 18 & 2.0 \\
\hline 4 hours up & 17 & 1.9 \\
\hline
\end{tabular}

According to the above data (See Table IB) multiple responses show that mail (14.0\%), finding data (13.1\%) and watching news $(11.9 \%)$ are the top three reasons for Internet access. After this comes the use of Blogs (10.1\%) at top 5; always reading and writing on a Blog platform, Wretch (40.3\%), Yahoo (22.1\%) and then Xuite (9.0\%); always reading and writing article classification, mood $(14.2 \%)$, entertainment $(12.4 \%)$, and then private space $(8.0 \%)$.

\section{B. IPA Results}

According to the reference about e-service quality, this research develop eight e-service quality index for evaluate the blog provider. The eight e-service quality indexes was show as the following:

- Blog's interface is smooth. (A1)

- Blog provides multiplicity functions. (A2)
- Blog provides multiplicity type of interface. (A3)

- Blog's web space is enough using. (A4)

- Blog grammar's limitation is widespread. (A5)

- To subscribe RSS. (A6)

- Teaching is clearing. (A7)

- To provide upload functions. (A8)

As shown in Fig. 1 for all the respondents to the IPA analysis, most fall into quadrant III (A3, A5, A6, A7), and then quadrant I (A1, A2, A8), with just a few in quadrant IV (A4), but quadrant IV is empty. On the other hand:

Quadrant I: Both performance and importance are high on this quadrant. So Blog can refer to A1, A2, A8 items and keep up the good work.

Quadrant II: In this quadrant, performance is low and importance is high, so the items here should be the first to be improved, but the study has no item for this.

Quadrant III: Both performance and importance are low in this quadrant. So A3, A5, A6, A7 should be the second to be improved.

Quadrant IV: Quadrant III and quadrant IV's performance is relative low, but quadrant IV' $\mathrm{s}$ importance is relatively high. A4 has importance enough, so that it should be improved first before quadrant IV and III to be more effective and beneficial.

"Blog interface is smooth", "Blog provides multiplicity functions" and "Upload functions are provided". These three functions are important and their performances are targeted to writers. These three functions have their advantages on blogs, so we should enhance the existing advantages to maintain the blogs' quality level.

"Web space provided by the Blog enough for normal use" is more important instead of performance. In conclusion, Blog' space is more important for users, but they are not the performances designated to them. Because the point is that Wretch is performed by $63.3 \%$ users, and if users want to increase space on Wretch they have to pay for it. So they can't upload many videos, photographs etc., and therefore the performance level drops.

As for "Blog provides multiple types of interface", "Blog grammar is widely limited"," To subscribe RSS", and" Teaching is clearing", these four functions are not important and its performance only matters for writers. In conclusion, the four functions are not necessarily entailed without any usage; however they have to re-plan and increase writers' performance and its importance felt by writers.

Impontance-Peformance Analysis

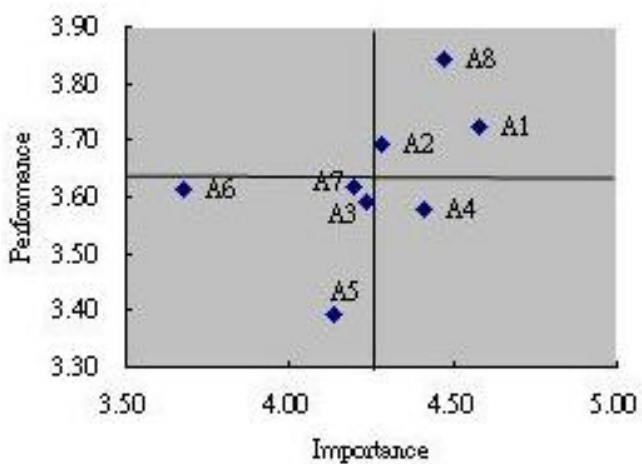

Fig. 1. Importance-performance analysis $(n=700)$. 
We group IPA into three groups: Gender, Time, and Top 2 blogs. Table II is independent samples t test results. As the gender group, A2, A4, A5, A7, and A8 are in the same quadrant, but their importance is significantly different. A3 is in another quadrant, and shown significant differences between females and males. The gender group of IPA results is as show the Fig. 2 and Fig. 3.

"Blog providing multiple types of interfaces" has different receptions between genders. Male views this with less importance and high performance; and female instead, views with high importance and less performance. The result has a significant difference, so we have to improve the functions to increase the perceptions of both male and female as far as both the importance and performance are concerned. Thus, as for "Blog provides multiplicity functions"," Web space provided by the Blog enough for normal usage"," Blog grammar is widely limited", " Teaching is clearing", and " Upload functions are provided", these five functions falls on the same quadrant for either gender, but the results from the five functional importance and performance criteria experience significant differences. In conclusion, we have improved and suggested further enhancements for these functions.

Males and females' importance rank: (1). Blog interface is smooth, (2).Upload functions are provided, (3). Web space provided by the Blog enough for normal use and performance rank: (1). Upload functions are provided, (2). Blog interface is smooth (3). Blog provides multiplicity functions. In conclusion, gender has same liking on these functions.

Impontance-Peffomance Aralysis

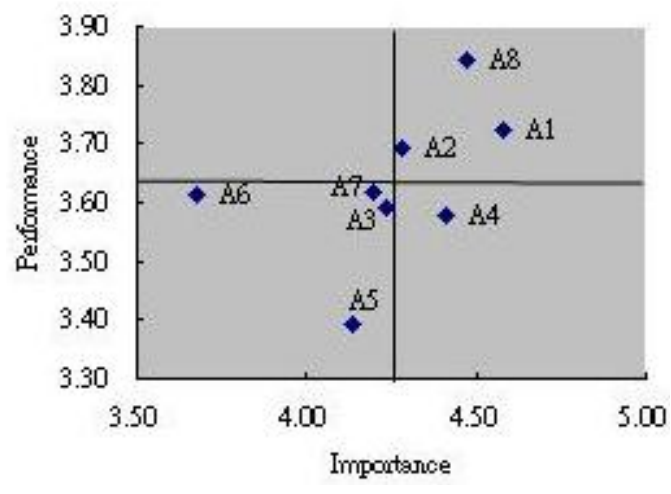

Fig. 2. Males' IPA ( $n=208)$.

Impoutance-Peffomance Aralysis (Female)

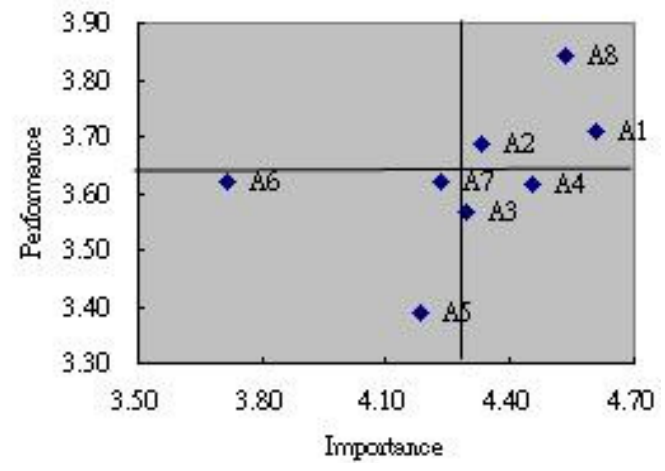

Fig. 3. Females' IPA $(n=492)$.
We group this using Blog time "under 30 minutes" and "30 minutes and over." The data show that A2 and A7 are in different quadrants, but the importance of A2 is significant difference. A4 is in quadrant IV, the importance is high and performance is low, we can improve it before the other quadrants except quadrant I.

The time that uses blogs every day can be grouped into two categories: "Under 30 minutes" and "30 minutes and over". "Blog provides multiplicity functions" and "Teaching is clearing" are on the different quadrants, but just the importance for "Blog provides multiplicity functions" has a significant difference in these groups. On the other hand, even though "Teaching is clearing" has different level of importance and performance respectively, but it hasn't the significant difference in these groups. "Blog provides multiplicity functions" has high importance and performance on these groups, but it has to be improved further so as to increase its importance.

"Under 30 minutes" importance rank: 1). Blog interface is smooth, 2). Upload functions are provided, 3). Web space provided by the Blog enough for normal use, and performance rank: 1). Upload functions are provided, 2). Blog interface is smooth, 3). Blog provides multiplicity functions;"30 minutes and over" importance rank: 1). Blog interface is smooth, 2)."Web space provided by the Blog enough for normal use" and Upload functions are provided, 3). Blog provides multiplicity functions, and performance rank: 1).Upload functions are provided, 2). Blog provides multiplicity functions, 3). Blog interface is smooth. In conclusion, the top 3 are different in sequence, but they also express have same liking on the three same functions.

Impontance-Pefomance Analysis (Under 30 minutes)

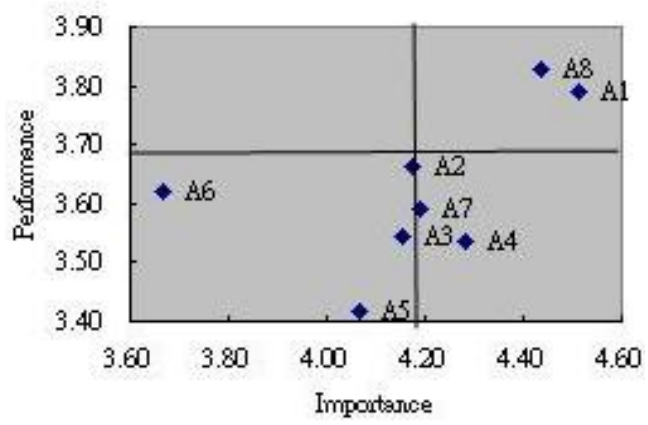

Fig. 4. Under 30 minutes IPA $(n=265)$

Impontance-Peffomance Aralysis (30 minutes and over)

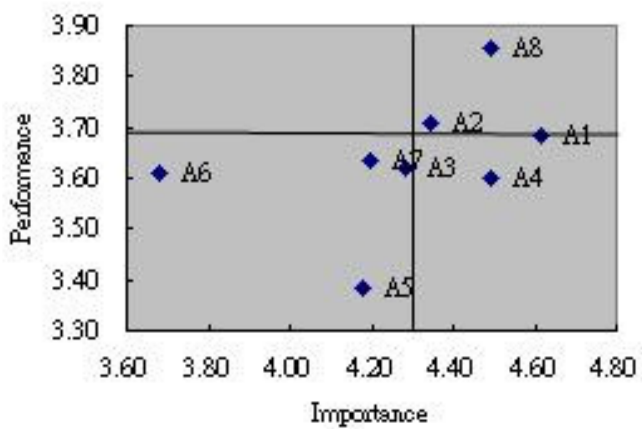

Fig. 5. 30 minutes and over IPA $(n=435)$. 
We also test the effect of different factor (gender and use of time) to the e-service quality. Table II and Table III indicated the t-test results. According to the t-test result, we can find that the gender is significant differences to the importance of blog's e-service quality, the index include "Blog provides multiplicity functions", "Blog provides multiplicity type of interface", "Blog's web space is enough using", "Blog grammar's limitation is widespread", "Teaching is clearing", and "To provide upload functions". The different the use blog of time is significant differences for the importance of e-service quality, there are "Blog's interface is smooth"," Blog provides multiplicity functions"," Blog provides multiplicity type of interface", "Blog's web space is enough using" and "Blog grammar's limitation is widespread".

TABLE II: INDEPENDENT SAMPLES T TEST (GENDER GROUP)

\begin{tabular}{llcccc}
\hline \hline & & $\begin{array}{c}\text { Female } \\
(n=492)\end{array}$ & $\begin{array}{c}\text { Male } \\
(n=208)\end{array}$ & $\begin{array}{c}\text { Mean } \\
\text { Difference }\end{array}$ & $t$-value \\
\hline \multirow{2}{*}{ A1 } & Importance & 4.61 & 4.51 & -0.09 & -1.68 \\
& Performance & 3.71 & 3.76 & 0.05 & 0.75 \\
\multirow{2}{*}{ A2 } & Importance & 4.33 & 4.16 & -0.17 & $-2.63^{* *}$ \\
& Performance & 3.69 & 3.70 & 0.01 & 0.23 \\
\multirow{2}{*}{ A3 } & Importance & 4.29 & 4.09 & -0.20 & $-3.14^{* *}$ \\
& Performance & 3.57 & 3.65 & 0.09 & 1.19 \\
A4 & Importance & 4.46 & 4.32 & -0.14 & $-2.27^{*}$ \\
& Performance & 3.61 & 3.49 & -0.12 & -1.47 \\
\multirow{2}{*}{ A5 } & Importance & 4.18 & 4.02 & -0.17 & $-2.43^{*}$ \\
& Performance & 3.39 & 3.41 & 0.02 & 0.27 \\
\multirow{2}{*}{ A6 } & Importance & 3.72 & 3.58 & -0.13 & -1.62 \\
& Performance & 3.62 & 3.59 & -0.03 & -0.49 \\
& Importance & 4.23 & 4.11 & -0.12 & $-1.70^{*}$ \\
A7 & Performance & 3.62 & 3.62 & 0.00 & -0.04 \\
& Importance & 4.53 & 4.33 & -0.21 & $-3.37^{* *}$ \\
& Performance & 3.84 & 3.85 & 0.01 & 0.13 \\
\hline \hline
\end{tabular}

TABLE III: INDEPENDENT SAMPLES T TEST (USER TIME GROUP)

\begin{tabular}{|c|c|c|c|c|c|}
\hline & & $\begin{array}{c}\text { Under } \\
30 \\
\text { minutes } \\
(n=265)\end{array}$ & $\begin{array}{c}30 \\
\text { minutes } \\
\text { and over } \\
(n=435)\end{array}$ & $\begin{array}{c}\text { Mean } \\
\text { Difference }\end{array}$ & $t$-value \\
\hline \multirow[t]{2}{*}{ A1 } & Importance & 4.51 & 4.62 & -0.11 & $-1.97 *$ \\
\hline & Performance & 3.79 & 3.69 & 0.10 & $1.68 *$ \\
\hline \multirow[t]{2}{*}{$\mathrm{A} 2$} & Importance & 4.17 & 4.35 & -0.17 & $-2.89^{* *}$ \\
\hline & Performance & 3.66 & 3.71 & -0.04 & -0.71 \\
\hline \multirow[t]{2}{*}{ A3 } & Importance & 4.15 & 4.28 & -0.13 & $-2.08^{*}$ \\
\hline & Performance & 3.54 & 3.62 & -0.08 & -1.10 \\
\hline \multirow[t]{2}{*}{ A4 } & Importance & 4.28 & 4.49 & -0.21 & $-{ }_{*}^{-3.55^{* *}}$ \\
\hline & Performance & 3.54 & 3.60 & -0.07 & -0.92 \\
\hline \multirow[t]{2}{*}{ A5 } & Importance & 4.06 & 4.18 & -0.12 & $-1.77^{*}$ \\
\hline & Performance & 3.42 & 3.38 & 0.03 & 0.48 \\
\hline \multirow[t]{2}{*}{ A6 } & Importance & 3.66 & 3.68 & -0.02 & -0.24 \\
\hline & Performance & 3.62 & 3.61 & 0.01 & 0.16 \\
\hline \multirow[t]{2}{*}{ A7 } & Importance & 4.19 & 4.20 & -0.01 & -0.14 \\
\hline & Performance & 3.59 & 3.63 & -0.05 & -0.68 \\
\hline \multirow[t]{2}{*}{ A8 } & Importance & 4.44 & 4.49 & -0.06 & -1.00 \\
\hline & Performance & 3.83 & 3.86 & -0.03 & -0.42 \\
\hline
\end{tabular}

We analyze for each blog provider (Google, Msn, Pchome,
Xuite, Yahoo, Wretch, PIXNET, Roodo, Sina and others), and test the importance and performance of the eight e-service quality index. Table IV and Table $\mathrm{V}$ provide in the analysis results. For MSN, PChome, Xuite, Yahoo, Wretch, PIXNET, Roodo, and Sina, they have high averages at the importance levels of "Blog interface is smooth", Google and other platforms have high averages for two functions of "Blog provides multiplicity type of interface", and "Web space provided by the Blog enough for normal use". In conclusion, we have to strengthen these three functional levels of importance.

"Blog interface is smooth" (PChome, Xuite, Yahoo, and Roodo) has exhibited many blogs' performances, and then followed by "To subscribe RSS" (Google, PIXNET, and Sina), and "Upload functions are provided" (MSN, Wretch, and Other) in ranking; and followed by "Web space provided by the Blog enough for normal use" (Roodo and Sina), and lastly, "Blog provides multiplicity functions" (Roodo)," Blog grammar is widely limited" (Roodo), and "Teaching is clearing" (Sina). In conclusion, these are the seven functions exhibited high performances on each blog, so we should keep up their levels of performance.

TABLE IV: IMPORTANCE AVERAGE SCORE FOR E-SERVICE QUALITY

\begin{tabular}{ccccccccc}
\hline & \multicolumn{8}{c}{ Blog e-service quality index } \\
Blog & A1 & A2 & A3 & A4 & A5 & A6 & A7 & A8 \\
\hline Google & 4.25 & 4.08 & 4.50 & 4.08 & 4.00 & 3.92 & 4.17 & 4.33 \\
Msn & 4.73 & 4.41 & 4.38 & 4.62 & 4.51 & 4.38 & 4.57 & 4.59 \\
Pchome & 4.71 & 4.00 & 4.43 & 4.43 & 4.57 & 3.57 & 4.71 & 4.57 \\
Xuite & 4.32 & 4.11 & 3.89 & 3.95 & 3.95 & 3.79 & 4.00 & 4.05 \\
Yahoo & 4.46 & 4.15 & 4.01 & 4.20 & 4.12 & 3.85 & 4.19 & 4.29 \\
Wretch & 4.60 & 4.30 & 4.26 & 4.44 & 4.10 & 3.57 & 4.15 & 4.52 \\
PIXNT & 4.57 & 4.38 & 4.33 & 4.48 & 4.38 & 4.05 & 4.43 & 4.52 \\
Roodo & 5.00 & 4.80 & 4.40 & 4.60 & 3.80 & 4.00 & 4.20 & 4.60 \\
Sina & 5.00 & 4.50 & 4.00 & 4.50 & 4.00 & 3.50 & 4.50 & 5.00 \\
Others & 4.58 & 4.33 & 4.30 & 4.70 & 4.36 & 3.70 & 4.42 & 4.48 \\
\hline \hline
\end{tabular}

TABLE V: PERFORMANCE AVERAGE SCORE FOR E-SERVICE QUALITY Blog e-service quality index

\begin{tabular}{ccccccccc} 
Blog & A1 & A2 & A3 & A4 & A5 & A6 & A7 & A8 \\
\hline Google & 4.00 & 3.67 & 3.17 & 3.58 & 3.25 & 4.25 & 3.50 & 3.92 \\
Msn & 4.22 & 4.11 & 4.03 & 4.19 & 3.86 & 4.08 & 4.19 & 4.27 \\
Pchome & 4.14 & 3.86 & 3.43 & 3.71 & 3.86 & 3.86 & 3.57 & 4.00 \\
Xuite & 4.00 & 3.53 & 3.68 & 3.79 & 3.53 & 3.63 & 3.42 & 3.58 \\
Yahoo & 3.92 & 3.69 & 3.56 & 3.60 & 3.51 & 3.67 & 3.64 & 3.70 \\
Wretch & 3.64 & 3.67 & 3.58 & 3.50 & 3.29 & 3.54 & 3.58 & 3.86 \\
PIXNET & 3.67 & 3.71 & 3.71 & 3.71 & 3.67 & 3.67 & 3.67 & 3.67 \\
Roodo & 3.80 & 3.80 & 2.80 & 3.80 & 3.80 & 3.80 & 3.40 & 3.60 \\
Sina & 3.50 & 3.50 & 3.50 & 4.00 & 3.50 & 4.00 & 4.00 & 3.50 \\
Others & 3.79 & 3.67 & 3.61 & 3.79 & 3.61 & 3.58 & 3.73 & 3.82 \\
\hline \hline
\end{tabular}

MSN, PChome, Xuite, Yahoo, Wretch, PIXNET, Sina and other platforms have low averages in the levels of importance at "To subscribe RSS" importance, and Roodo has low average for "Blog grammar is widely limited ". In conclusion, these two functions have to be re-planned so as to increase their levels of importance.

"Blog grammar is widely limited" (MSN, Yahoo, Wretch, 
PIXNET, and Sina) exhibited many blog performances but is less in average, and then followed by "Blog provides multiplicity type of interface" (Google, PChome, Roodo, and Sina), and again followed by "Blog interface is smooth" (PIXNET and Sina), "Teaching is clearing" (Xuite and PIXNET), and "Upload functions are provided" (PIXNET and Sina), and trailed by "Blog provides multiplicity functions" (Sina), and " To subscribe RSS"(Other platforms). In conclusion, the seven functions have to be improved and their performance levels must be increased.

\section{CONCLUSION AND SUGGESTION}

The study concludes that by using blog in analyzing the experience of blog usage and multiple responses, three of these findings are summarized as follow:

1) When the rate of blog usage is high, it expects that receiving mail, finding data, and watching news are what respondents usually do. Wretch is often used $(63.3 \%)$ than the other blogs and express what most famous of these blogs.

2) $62.6 \%$ of the Internet access time lasts over 3 hours, $54.1 \%$ in usig the blog time lasts over 30 minutes, $77.8 \%$ respondents have never written a blog, and $79.3 \%$ respondents have their own blogs. From multiple responses in gender classification, when they go Internet access, the top male and female rankings on using blog are 7 and 4 respectively, and all the respondents are in top 5. In conclusion, Wretch has its fame on blogs.

3) In the aspect of article' classification, most of the writer and reader classifications on blogs focus on mood expression, entertainment, and private space groups, and from all the respondents, mood expression group is the most important classification. In conclusion, respondents often express their moods through blogging that can impute the social stress, competition, and economical depression, so they can vent their dissatisfactions or angers this way. From the datum, we also can found that blogs are most used focus on students $(51.3 \%)$. It shows that users who are youthful on using blogs in Taiwan.

Blogs can generate in-depth effects for users. In recent years, referencing request on blogs is on the rise. During this period, online culture also has pushed envelop for interpersonal interaction. We should confront and address these problems proactively, and hope that with service improvements and technological innovations, the user's incessant asking the service providers to achieve the high levels of importance and performance for each function implemented; this should not be surprising after all.

Blogs can provide users with some help, and allow them grow confidences on blogs. We suggest service providers adopt strategies like: For first-time blog users, they can be treated with certain innovations which would make users feel they would be interested. And with gradual addition with ease of usage, and their perceived usefulness would increase as well. Sometimes, they even can have activities on blogs to increase blog usages, interactions with other users, which would eventually lead the users closer to the heartbeat of the market.

\section{ACKNOWLEDGMENT}

The authors thank Kitty Li for her help about the collection questionnaire in this research.

\section{REFERENCES}

[1] C. L. Hsu and J. C. C. Lin, "Acceptance of blog usage: The roles of technology acceptance, social influence and knowledge sharing motivation," Information and Management, vol. 45, pp. 65-74, 2008.

[2] S. I. Todoroki, T. Konishi, and S. Inoue, "Blog-based research notebook: Personal informatics workbench for high-throughput experimentation," Applied Surface Science, vol. 252, pp. 2640-2645, 2005.

[3] L. N. Carolina, J. Francisco, and B. Harry, "An assessment of advanced mobile services acceptance: Contributions from TAM and diffusion theory models," Information and Management, vol. 45, pp. 359-364, 2008.

[4] A. Parasuraman, V. A. Zeithaml, and L. L. Berry, "A conceptual model of service quality and its implications for future research," Journal of Marketing, vol. 49, no. 4, pp. 41-50, 1985.

[5] K. Ruyter, J. Bloemer, and P. Peeters, "Merging service quality and service satisfaction an empirical test of an integrative model," Journal of Economic Psychology, vol. 18, pp. 387-406, 1977.

[6] D. M. Lambert, R. S. James, and J. U. Sterling, "A gap analysis of buyer and seller perceptions of the importance of marketing mix attributes," Enhancing Knowledge Development in Marketing, Chicago: American Marketing Association, 2008.

[7] A. Parasuraman, V. A. Zeithaml, and A. Malhotra, "E-S-QUAL: A multipleitem scale for assessing electronic service quality," Journal of Service Research, vol. 7, pp. 213-233, 2005.

[8] M. Fassnacht and I. Koese, "Quality of electronic service: conceptualizing and testing a hierarchical model," Journal of Service Research: JSR, vol. 9, pp. 19-37, 2006.

[9] A. Parasuraman, V. A. Zeithaml, and A. Malhotra, "E-S-QUAL: A multipleitem scale for assessing electronic service quality," Journal of Service Research, vol. 73, pp. 213-233, 2005.

[10] P. A. Dabholkar, C. D. Shepherd, and D. I. Thorpe, "A comprehensive framework for service quality: An investigation of critical conceptual and measurement issues through a longitudinal study," Journal of Retailing, vol. 76, pp. 139-173, 2000.

[11] R. L. Oliver, "A cognitive model of the antecedents and consequences of satisfaction decisions," Journal of Marketing Research, vol. 17, pp. 460-469, 1980.

[12] G. G. Lee and H. F. Lin, "Customer perceptions of E-Service quality in online shopping," International Journal of Retail and Distribution Management, vol. 33, pp. 161-176, 2005.

[13] M. Wolfinbarger and M. C. Gilly, "e-TailQ: Dimensionalizing, measuring and predicting etail quality," Journal of Retailing, vol. 79, pp. 183-198, 2003.

[14] M. Fassnacht and I. Koese, "Quality of electronic service: conceptualizing and testing a hierarchical model," Journal of Service Research: JSR, vol. 9, pp. 19-37, 2006.

[15] P. A, Dabholkar, C. D. Shepherd, and D. I. Thorpe, "A comprehensive framework for service quality: An investigation of critical conceptual and measurement issues through a longitudinal study," Journal of Retailing, vol. 76, pp. 139-173, 2000.

[16] N. M. Levengurg and S. R. Magal, "Applying importance-performance analysis to evaluate e-business strategies among small firms," E-Service Journal, vol. 3, pp. 29-49, 2005.

[17] W. Deng, "Using a revised importance-performance analysis approach: The case of Taiwanese hot springs tourism," Tourism Management, vol. 28, pp. 1274-1284, 2007.

[18] J. A. Martilla and J. C. James, "Importance-performance analysis," Journal of Marketing, vol. 41, pp. 77-79, 1977.

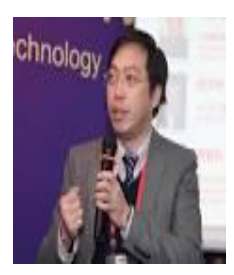

Yu-Kai Huang is an assistant professor of Department of Culture and Creative Enterprise Management, Nanhua University. He earned his Ph.D. at the Chiao Tung University (Taiwan). After earning his $\mathrm{PhD}$, he worked as a logistics and marketing manager for several e-commerce organizations. His research interests include logistics management, electronic commerce, marketing management, catastrophe theory, chaos behavior and nonlinear dynamic system. Recently, his research focus on issues relating to logistics and supply chain integration, as well as issues relating to the role of -e-commerce in the definition of 
strategies and performance in supply chain management and on implementation decisions involving information systems and inventory managements.

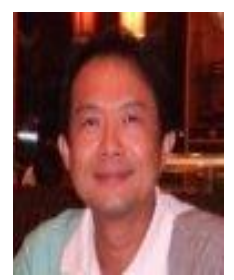

Wei-shang Fan is an associate professor of Department of Management of Administration, Nanhua University. He earned his Ph.D. at the Chung-Chen University (Taiwan). After earning his $\mathrm{PhD}$, he served as a consult of Entrepreneur programs and marketing instructors for Taiwan government and international companies. His research interests include electronic commerce, marketing management, market analysis and research, entrepreneurship management.

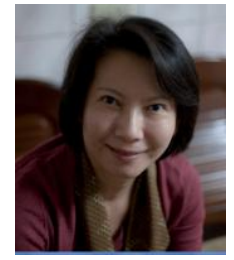

Ming-Chun Tsai is an assistant professor of Department of Business Administration, Ling Tung University, Taiwan, She also a Ph.D. Candidate in Business School at the University of Feng Chia in Taiwan. She received her master's degree from Greenwich University in United Kingdom. Assistant professor Tsai has contributed many articles to the journals. She has worked with companies on marketing research, marketing strategy and quality management. 